\title{
Effects of Ratcheting Strain on Cyclic Time-Dependent Parameters of Salt Rocks
}

\author{
Farhang Sereshki ${ }^{a}$ and Amir Saffari ${ }^{\text {b }}$ \\ ${ }^{a}$ Associate Professor, Faculty of Mining Engineering, Petroleum and Geophysics \\ Shahrood University of Technology, Shahrood, Iran \\ farhang@shahroodut.ac.ir \\ ${ }^{b} \mathrm{Ph} . \mathrm{D}$ Candidate, Faculty of Mining Engineering, Petroleum and Geophysics \\ Shahrood University of Technology, Shahrood, Iran \\ amirsaffari5710@yahoo.com
}

\begin{abstract}
Salt rock is a particular medium for underground storage of natural gas. From the view point of operation of salt caverns, a seasonal storage pattern has been applied so far. However, more frequent cycling of internal pressure in terms of mass flow and pressure gradients is required today. The objective of the current study is to find the relationship between ratcheting strain pattern and cavern closure during their operational life. For this purpose, an experimental investigation is used to assess the effect of ratcheting pattern on timedependent properties of the host rock. The results reveal that viscoelastic and viscoplastic parameters of the rock salt exponentially decrease by increasing the loading frequency and deviatoric stress amplitude. Also, viscoplastic coefficients are much more sensitive to the frequency of pressure fluctuations.
\end{abstract}

Keywords: Salt cavern, creep, ratcheting, constitutive model, natural gas storage

\section{INTRODUCTION}

Salt formations are important alternatives for underground storage of natural gas in many countries. The main advantages of salt are its relatively high ductility, very low permeability and porosity [1]. During the last thirty years, storage of gas in salt caverns has been developed rapidly. From the view point of operation mostly a seasonal storage pattern has been applied so far. According to increasing demands of the international gas market, cavern storage operators are asking more operation patterns characterized by more frequent cycling of internal pressure at higher rates in terms of mass flow and pressure gradients [2]. In addition to establishing safe cavern operations reflecting associated operating parameters, the rock mechanical evaluation should also provide an assessment of cavern stability. This evaluation involves describing the future rock deformation or cavern closure effect on the basis of the calculation results and comparing them with the operation specifications or the requirements of the operator.

For design and analysis of these types of structures, accurate prediction of ratcheting response is critical as it can lead to catastrophic failure of the structures where the plastic strain exceeds the critical limit of the rock surrounding the cavern. Also, volume loss associate with frequency of fluctuations in internal pressure are determined by time-dependent calculations of the cavern deformation taking into consideration realistic internal pressure change over time.

Thus, the host rock behavior under such condition must be given special consideration when determining the rock mechanical layout of cavern in rock salt.

The aim of the current study is to determine experimentally the effects of ratcheting strain on deformation behavior and rheology of the rock salt.

\section{LITERATURE REVIEW}

The behavior of salt rock under static loading has been thoroughly studied [3-8]. The effect of cyclic loading on the mechanical properties of geologic material has long been recognized. Burdine first showed that compressive cycling of rock resulted in a schematic weakening of the material [9]. Hardy and Chugh [10], Attewell and Farmer [11], Badge and Petros [12,13] and others perform many tests on a variety of rock types, which clearly demonstrated the progressive weakening of rock due to 
cyclic loading. However, Reaction of salt rocks to the repetitive stresses caused by cyclic loads has been generally neglected with the exception of a few rather limited studies. Thoms and Gehle conducted triaxial cyclic loading with low frequency by imitating the actual loading condition of compressed air energy storage caverns. They concluded at the higher stress level the number of cycles that causes failure is less than that in the lower stress level [14].

Passaris performed low frequency cyclic loading test to design compressed air energy storage. He showed the strain softening behavior of rock salt affected the elastic module of the rock by increasing number of cycles [15].

Fuenkajorn and Phueakphum performed comprehensive experimental studies on the impact of cyclic loading on the mechanical behavior of salt rock on one of Thailand basin. They concluded that the effect of loading frequency on the salt strength appears to be small and compared to the impact from the magnitudes of the maximum load and the loading amplitude. Also, they showed that time dependent parameters of salt rock were decreased by increasing applied octahedral shear stress [16]. Also, considerable studies have focused on numerical modeling of salt caverns subjected to cyclic loading $[17,18]$.

\section{DEFINITION OF THE RATCHETING STRAIN}

Ratcheting can be defined as accumulation of plastic strain with the application of cyclic loading characterized by a non-zero mean stress [19]. After a sufficient number of cycles the total strain (displacement) become so large that the original shape of the structure is altered, thereby making it unserviceable. This phenomenon is characterized by a translation of the hysteresis loop under asymmetrical loading condition. Ratcheting behavior is giving the same nature as creep strain. Stages of ratcheting strain splits into three regions as the creep strain development under static load: the primary (transient), secondary (steady-state) and tertiary (accelerating) regions [20].

It is important in designing and life evaluation of the structures endured in cyclic loading. Ratcheting strain has a great dependence on loading conditions and loading history. Other factors, such as ambient temperature and non-proportionality of loading path, have significant effects on ratcheting.

The axial ratcheting strain can be defined as cumulative strain in center of the current hysteresis loop in last cycle. It is defined in Equation 1 [20].

$$
\varepsilon_{r}=\frac{\left(\varepsilon_{\min }+\varepsilon_{\max }\right)}{2}
$$

Where $\varepsilon_{r}, \varepsilon_{\max }$ and $\varepsilon_{\min }$ are the ratcheting, maximum and minimum axial strain in each cycle respectively.

\section{Creep Law}

To take the ductile behavior of rock into consideration as realistically as possible, an efficient material model must be used. LUBBY2 constitutive is especially developed for time-dependent behavior of salt rock. There are several other constitutive models have been developed for describing the salt behavior [21-23]. Some models are very sophisticated and capable of handling complex thermomechanical behavior. This model includes both the transient and the steady-state creep phase with additive superposition of the primary creep strain rate either with time hardening (Equation 2) or with strain hardening (Equation 3) and of the secondary creep strain rate [17].

$$
\begin{aligned}
& \dot{\varepsilon}(t)=\left[\frac{1}{\bar{\eta}_{k}(\sigma)} \exp \left(-\frac{\bar{G}_{k}(\sigma)}{\bar{\eta}_{k}(\sigma)} t\right)+\frac{1}{\bar{\eta}_{m}(\sigma)}\right] \times \sigma \\
& \dot{\varepsilon}\left(\varepsilon_{e}\right)=\left[\frac{1}{\bar{\eta}_{k}(\sigma)}\left(1-\frac{\varepsilon_{e} \cdot \bar{G}_{k}(\sigma)}{\sigma}\right)+\frac{1}{\bar{\eta}_{m}(\sigma)}\right] \times \sigma
\end{aligned}
$$

Where, $\dot{\varepsilon}$ is effective creep strain rate, $\varepsilon_{e}$ is effective creep strain, $\sigma$ is effective stress, $\bar{\eta}_{m}, \bar{G}_{k}$ and $\bar{\eta}_{k}$ are coefficients of Maxwell viscosity, Kelvin shear module and Kelvin viscosity respectively which are stress dependent. 
Creep parameters of the LUBBY2 constitutive model can be determined from multi-level loading. This procedure minimizes the effect of fluctuations in mechanical properties of samples. Therefore, a more uniform result can be achieved and the number of required specimens will be decreased. The procedure of step-wise creep test can be found in previous studies [24, 25].

Multi-level loading can also be used in cyclic loading application to calibrate creep parameters of specimens. In this case, load increase step-wise in each block of cycles as shown in Figure 1.

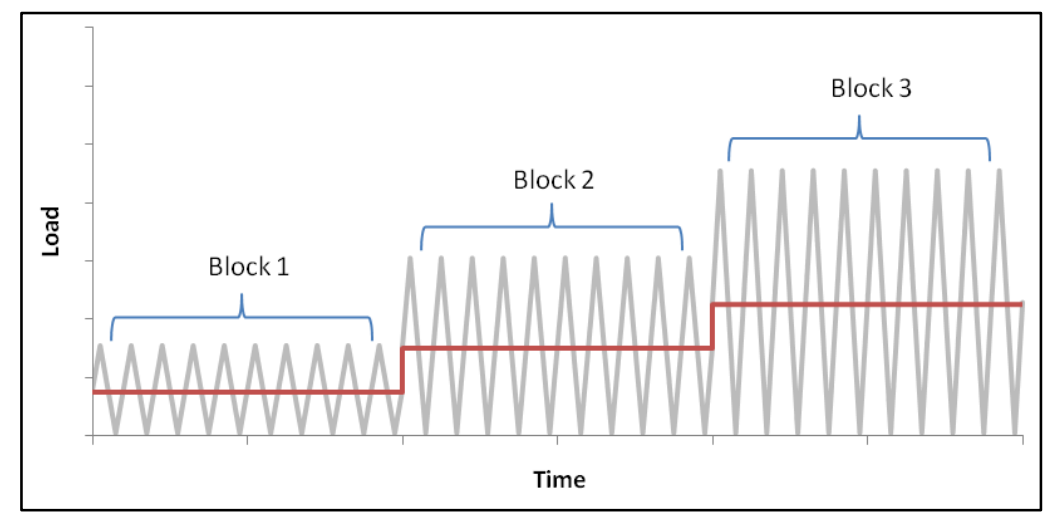

Figure1. Multi-Level Loading In Cyclic Application

The dependence of the cyclic creep rate on stress is taken into account using stress dependent parameters $\bar{\eta}_{m}, \bar{G}_{k}$ and $\bar{\eta}_{k}$. Detailed discussion on the subject and determination of the cyclic creep variables are presented in section 4.4.

\section{EXPERIMENTAL INVESTIGATION}

\subsection{Samples Preparation}

In this paper, rock salt refers to rock with dominant mineral component of halite, whereas salt rock is a more general designation for all rocks with a dominant mineral component of highly soluble salts generally of evaporitic origin [26].

The core samples with a nominal diameter of $54 \mathrm{~mm}$ were cored from Kouhdasht Kohan salt mine in Semnan province, Iran. The studied area is located in a structural region called Central Iran, 100 kilometers of southeast of Tehran (Figure 2). The mining method in this mine is irregular room and pillar mining.

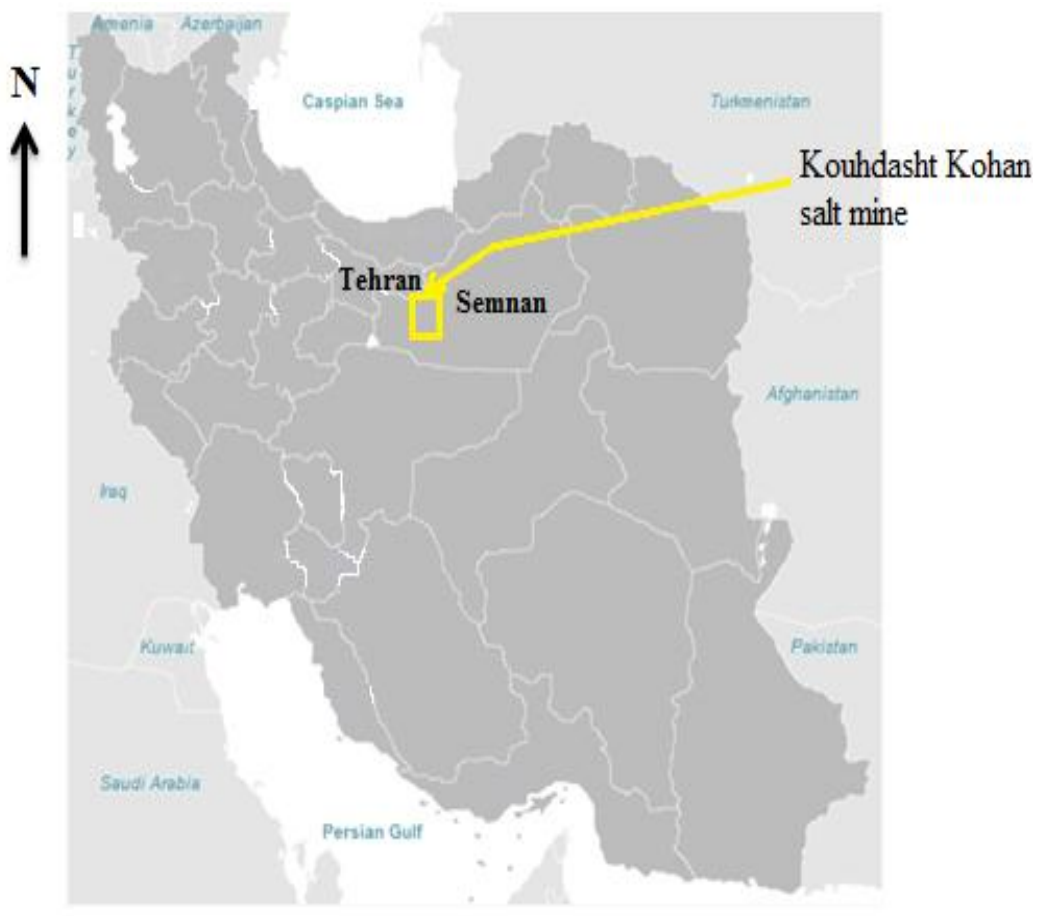

(a) 


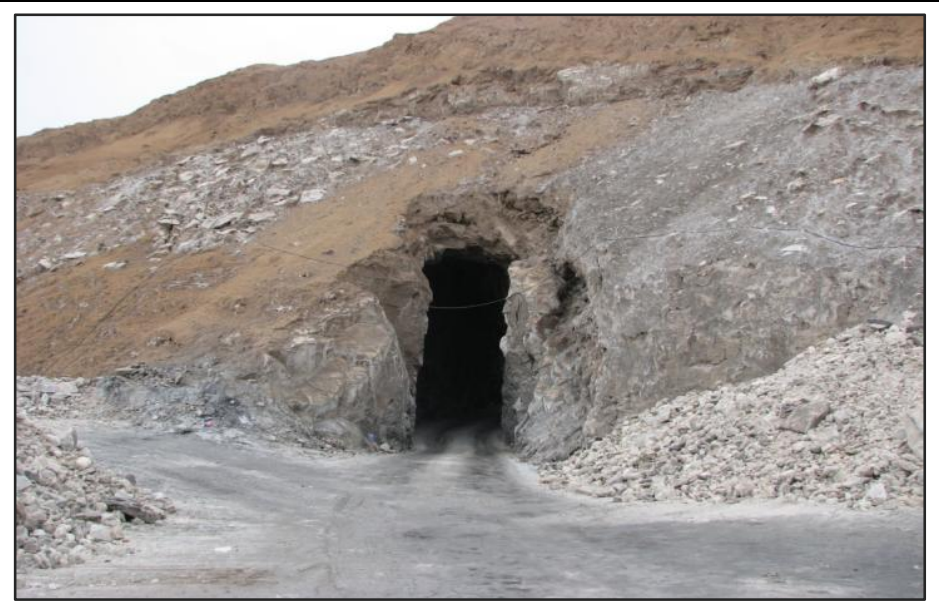

(b)

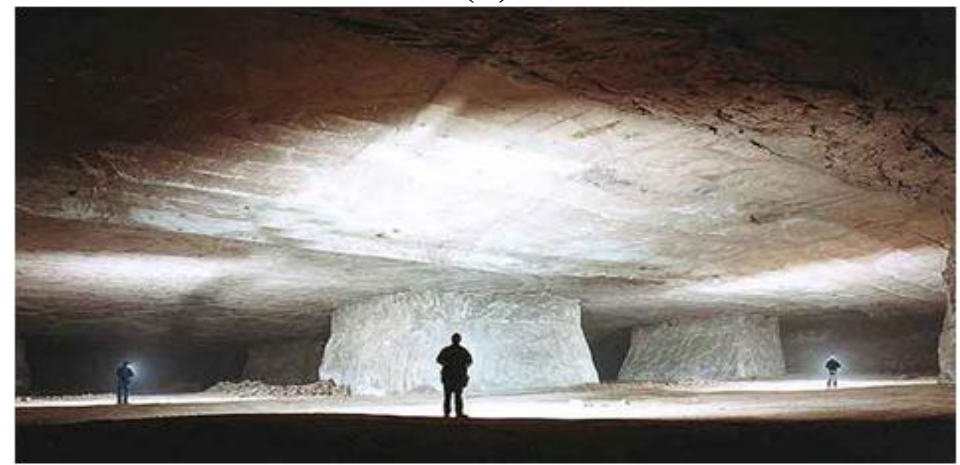

(c)

Figure2. (a). Approximate location of the Kouhdasht Kohan salt mine in Semnan, Iran. (b). Intake of Kouhdasht Kohan salt mine. (c). Irregular pillars in Kouhdasht Kohan salt mine which are extracting with room and pillar mining.

Most of the coring problems were directly related to the internal structure of the salt. It was a soft material with a crystalline structure, extremely brittle, especially when unconfined and subjected to high temperature and also severely soluble in water. It was not possible to use dry coring procedures as thermal stress in rock samples is caused thereby. Similarly, water could not be used since it dissolves the sample surface and changes its characteristics. In the final drilling procedure, cores were drilled using saturated brine as drilling fluid. Coring was conducted at low rotation speed of core barrel and small trust approximately equivalent to the self-weight of the barrel.

\subsection{Testing Equipment}

All experiments were performed using servo-controlled testing equipment INSTRON-8802 (Figure 3) the axial load and displacement were controlled by the equipment's control system. The maximum load capacity of the frame is $2.5 \times 102 \mathrm{kN}$. Loading rate, frequency, amplitude and other testing configurations can be varied with the servo-control system.

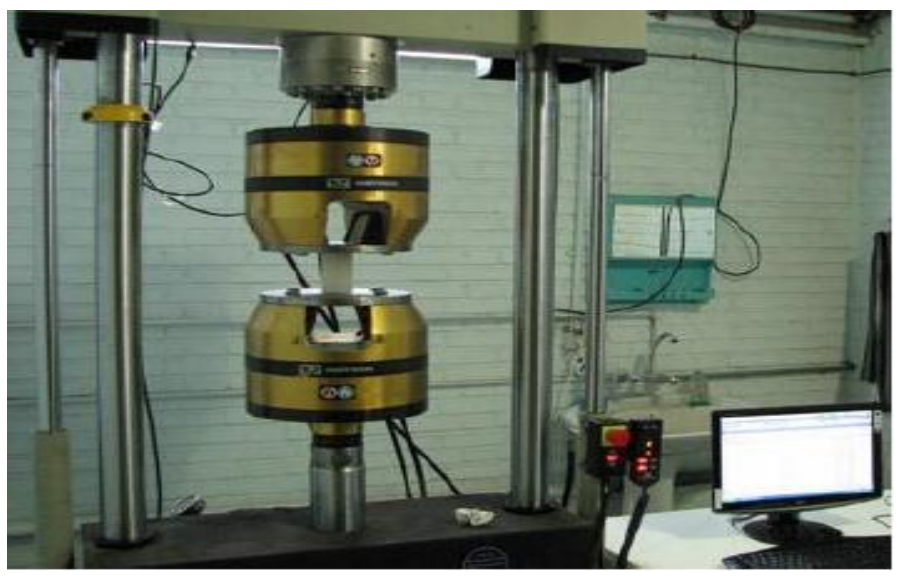

Figure3. INSTRON 8802 servo-controlled testing equipment 


\subsection{Testing Procedure}

To determine the test parameters of the salt samples for the subsequent cyclic loading tests, five uniaxial compression and four indirect tensile tests were performed based on ISRM standards.

The average uniaxial compressive and Brazilian tensile strengths are $28.7 \mathrm{MPa}$ and $1.54 \mathrm{MPa}$. Because of ductile behavior of salt, average elastic module is determined from unloading curves in uniaxial cyclic loading tests and it is equal to $9.41 \mathrm{GPa}$. It is recognized that the average elastic module of the tested rock salt is consistently lower than that of other researchers presented in their studies [23]. It is believed the reason for the lower stiffness is that the younger deposit should somewhat weaker and less stiff than salt from older deposit. Also, domal salts are less porous than bedded salts and older salts are less porous that younger salts in general [26].

In order to establish exact rheological mechanical models of salt rock under repetitive loads, cyclic creep tests must be adopted. For this purpose a compressive loading frequency of $0.05 \mathrm{~Hz}$ is applied to compare with the quasi-static test result which presented in authors paper [27].

It should be noted that the loading frequency is significantly higher than those induced by the actual operation of gas storage cavern. However, an overall trend between quasi-static and cyclic test results is expected.

Ten specimens prepared for cyclic creep test to have length/diameter ratio greater than two. To minimize the dynamical effect of loading waveform and keep it constant during the cyclic tests, a ramp waveform is used. Based on Xiao et al. studies, at the same load point the average loading rate under sine and square waveforms are always greater that under ramp waveform [27].

Six specimens used to calibrate visco-plastic parameters by conducting long-term cyclic creep tests and three are used to adjust visco-elastic coefficients using short term step-wise cyclic creep test.

\subsection{Experimental Results}

During the process of loading and unloading in cyclic uniaxial creep tests, samples harden up to a certain number of cycles and gradually stabilize. It can be interpreted as hysteresis loops compaction and hardening behavior of specimens (Figure 4). However, ratcheting keeps on occurring with cycles even after the salt deformation rate stabilizes. It increases continuously with number of cycle as plastic strain accumulated with time and material is finally failed due to large plastic strain. Figures 4 and 5 show cyclic hardening of sample $\mathrm{L} 1$ under $35 \mathrm{kN}$ axial load and its ratcheting strain bounded by maximum and minimum strain in each cycle.

It should be noted that in some experiments, low deviatoric stress level leads to ratcheting strain comes to a constant value and no more plastic strain induced in the material structure. It shows that specimens don't fail due to ratcheting. This behavior is known as shake-down of material under cyclic loading. Therefore, salt samples depend on applied deviatoric stress illustrate both ratcheting and shake-down response with the application of cyclic loading.

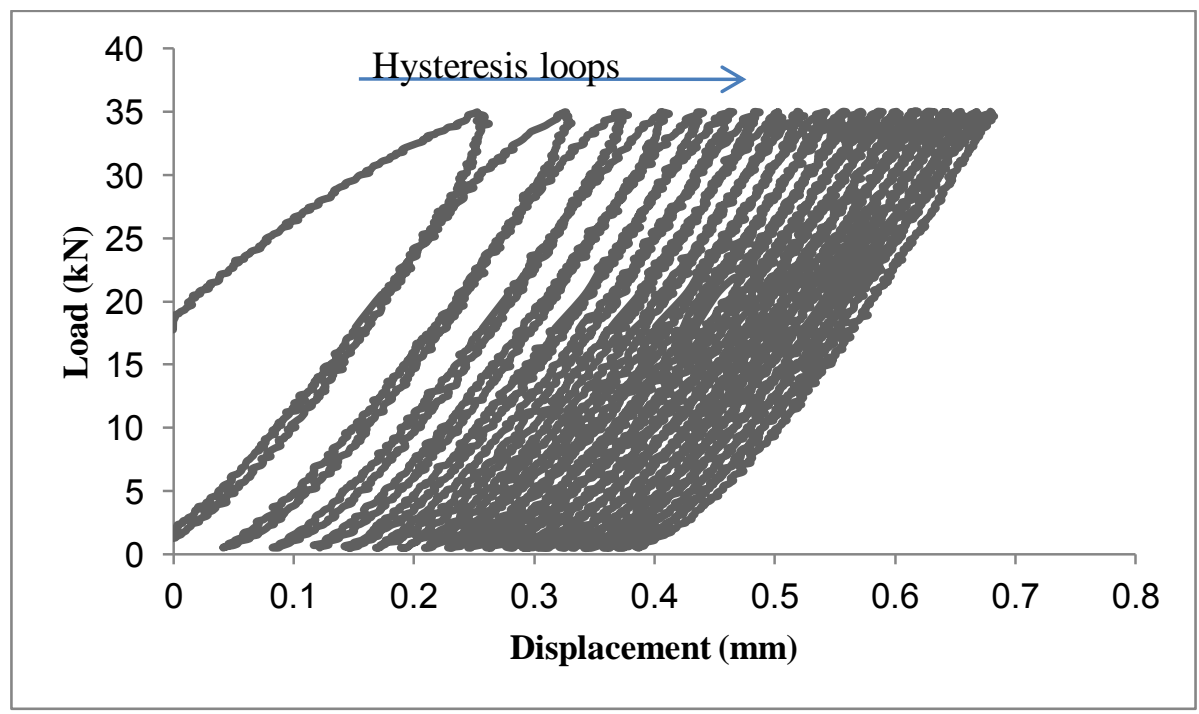

Figure4. Cyclic hardening response of sample No. 1 in initial cycles of the ratcheting test 


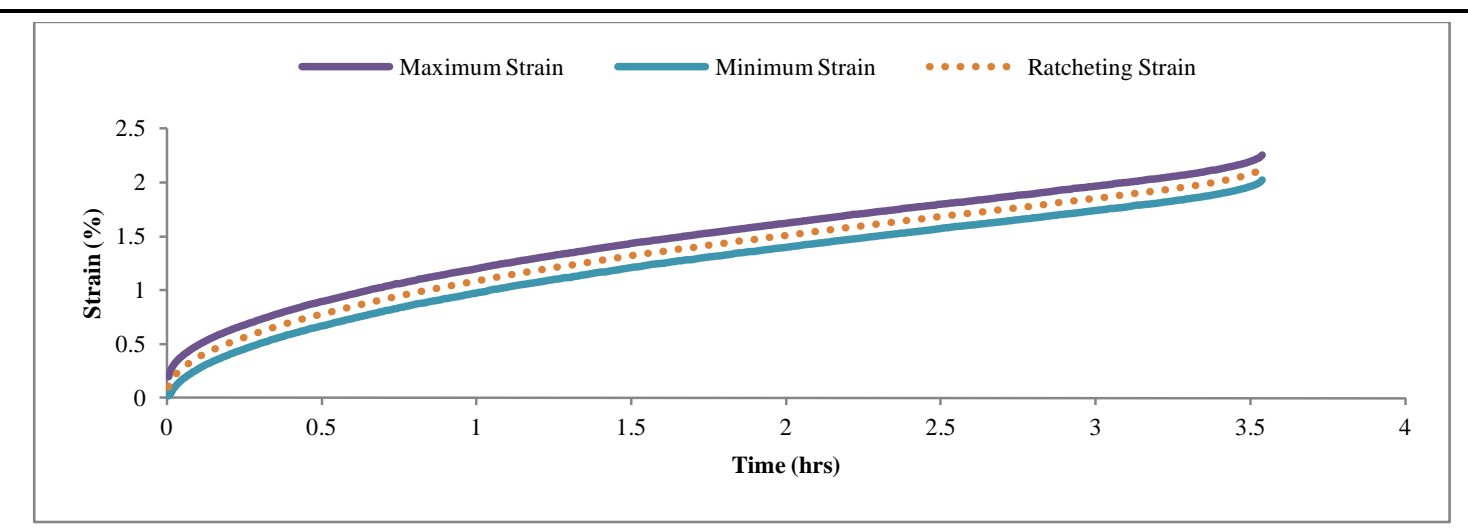

Figure5. Axial ratcheting creep curve accompanied by max/min strain-time curves

The ratcheting curve of specimens can be divided different stages. At first, compressive load in the initial cycle can lead to closing microcracks or pore spaces oriented at suitable angle to the applied stress. Of course it is less obvious for salt rocks as they have low porosity and self- healing ability. However, there is usually intercrystalline extensional damage from the sampling and de-stressing process. Next, with further compaction, specimens enter to an elastic stage. This only occurs if effective stress had a lower magnitude than salt yield strength. During this stage, most of the deformations are recoverable. Its upper boundary is the point of maximum compaction and zero volume change. Continuing compression results in volume change and plastic strains induced in the sample. Each cycle demonstrates same manner as discussed above. In spite of the fact that cumulative plastic strain increase continuously, plastic strain rate decrease gradually. It is because of salt mechanical behavior as a strain-hardening material. It can be concluded that the total ratcheting strain is composed of instantaneous elastic recovery strain, delayed elastic recovery strain and residual strain of the specimens which demonstrate the existence of elastic, plastic and viscous strains in ratcheting experiments.

To allow further evaluation of data, it is first necessary to resolve multi-level loading tests into single individual test and constant mean load. For this purpose, total strain due to transient creep in each load step consider to be equal to the additive superposition of the primary creep strain component of the previous load steps and that of the present load step. Figure 6 shows the results of the multi-level cyclic loading on one of the salt samples using this approach.

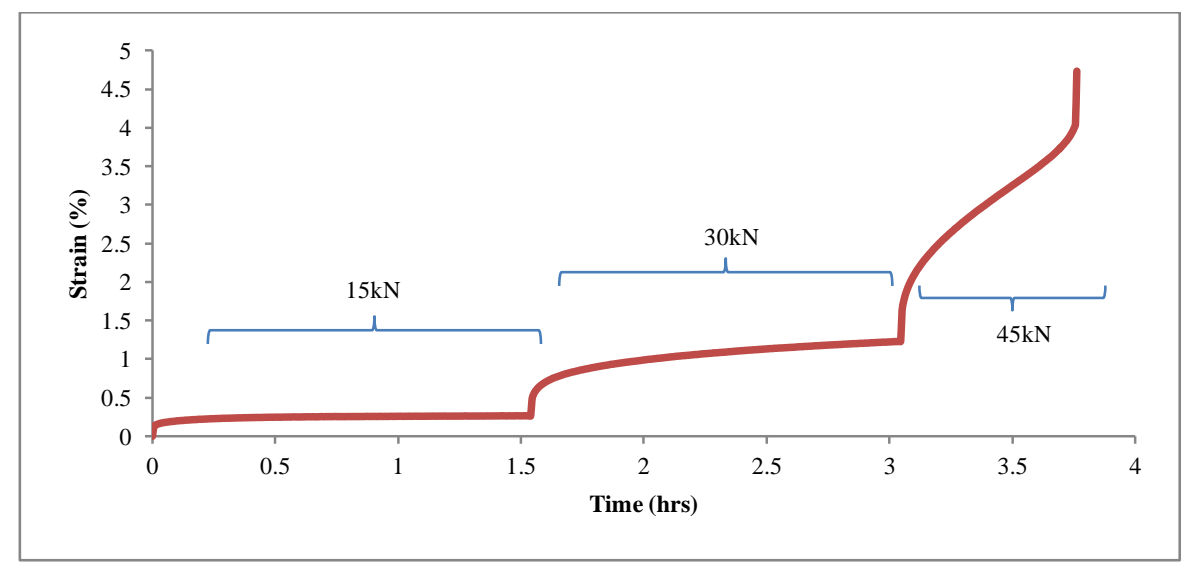

Figure6. Example of a step-wise ratcheting test

The dependence of the cyclic creep rate on stress is considered using stress-dependent creep components. The procedure used to determine LUBBY2 creep parameters using Equation 4 to 9 [17, 29].

$\bar{\eta}_{M}=\bar{\eta}_{M}^{*} e^{m \sigma}$
$\bar{G}_{K}=\bar{G}_{K}^{*} e^{k_{1} \sigma}$ 
$\bar{\eta}_{K}=\bar{\eta}_{K}^{*} e^{k_{2} \sigma}$

Exponential regression among several pairs of effective stress and Equation 7 through 9 can be used to determine LUBBY2 stress dependent parameters.

$$
\begin{aligned}
& \bar{\eta}_{M}=\frac{\sigma}{\dot{\varepsilon}_{s}} \\
& \bar{G}_{K}=\frac{\sigma}{\varepsilon_{a t r}} \\
& \bar{\eta}_{K}=\frac{\bar{G}_{K} t}{\ln \left(\frac{\varepsilon_{a p r}-\varepsilon_{p r}}{\varepsilon_{a p r}}\right)}
\end{aligned}
$$

Where, ${ }^{\dot{\varepsilon}_{s}}$ is the steady-state creep strain rate, ${ }^{\varepsilon_{a p r}}$ is the adjusted primary creep strain, ${ }^{\varepsilon_{p r}}$ is primary creep strain, $m, k_{1}$ and $k_{2}$ are constants.

Cyclic creep parameters determined from different amplitude and mean load level are presented in Figures 7-8.

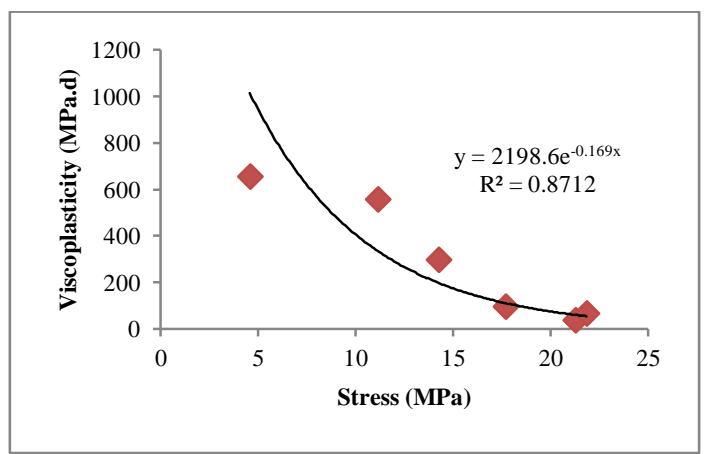

Figure7. Stress-dependent viscoplasticity as function of effective stress

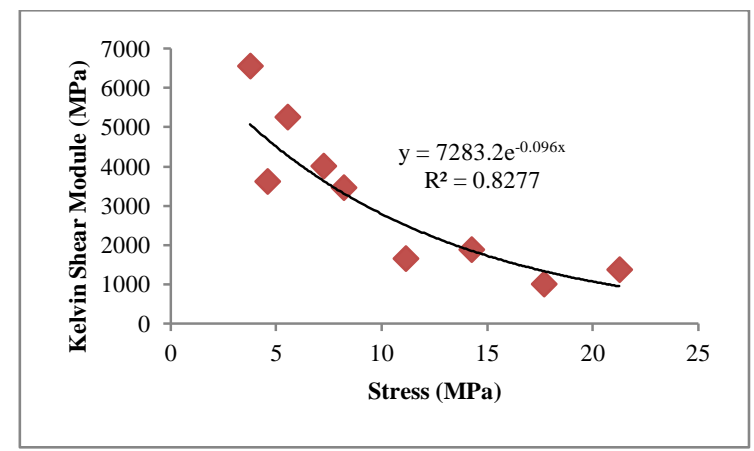

(a)

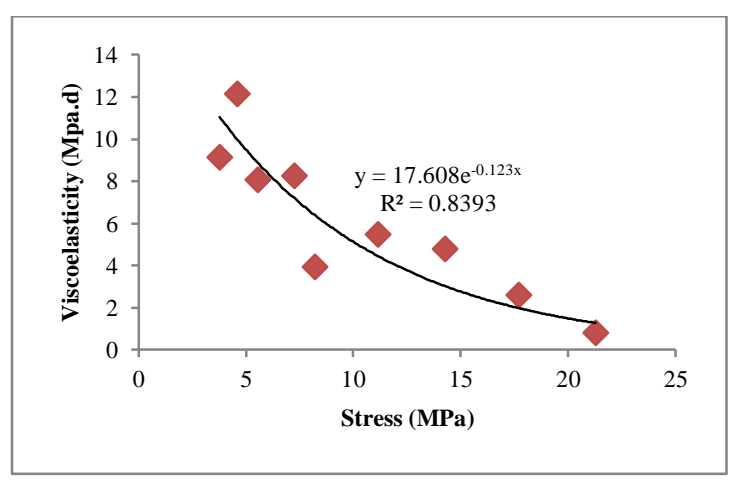

(b)

Figure8. A-Stress-dependent Kelvin shear module, b-Stress-dependent viscoelastic coefficient

Results reveal that the cyclic steady-state creep strain rate increases as deviatoric stress increases. The same conclusion can be drawn for primary and total cyclic creep strains. These parameters control creep deformation of specimens under cyclic loading application. To compare these results with the outcomes of quasi-static tests, which presented in [27], each pair of diagrams is plotted in a same chart. Therefore, viscoelastic and viscoplastic coefficients calculated for both creep and ratcheting tests are plotted as a function of applied stress in Figure 9. 
It can be concluded that viscoelastic and viscoplastic parameters of salt decrease exponentially with increasing loading frequency (Figure 9). Also, the effect of loading frequency on viscoplastic parameters of the specimens is extremely higher than that of viscoelastic coefficients (Figure 9a). It means that assessment of the long-term stability of the cavern requires sufficient attention to the impact of ratcheting strains on long-term time-dependent properties of the rock mass surrounding the cavern.

Also, loading amplitude showed a significant impact on the time-dependent parameters of the salt. Higher loading amplitude causes much lower deformation resistivity of salt sample both in short and long terms. It reveals that deeper salt caverns are more sensitive to injection/withdrawal frequencies and pressure fluctuations as larger dynamic forces intermittently applied to the structure.

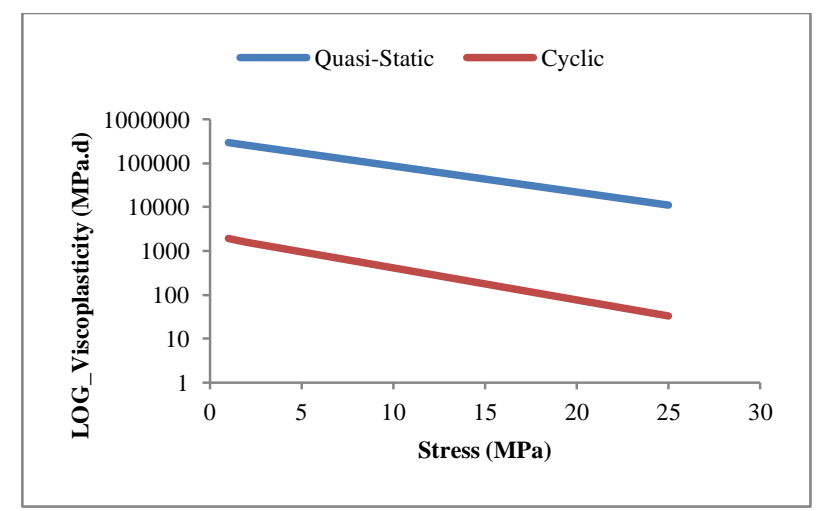

(a)

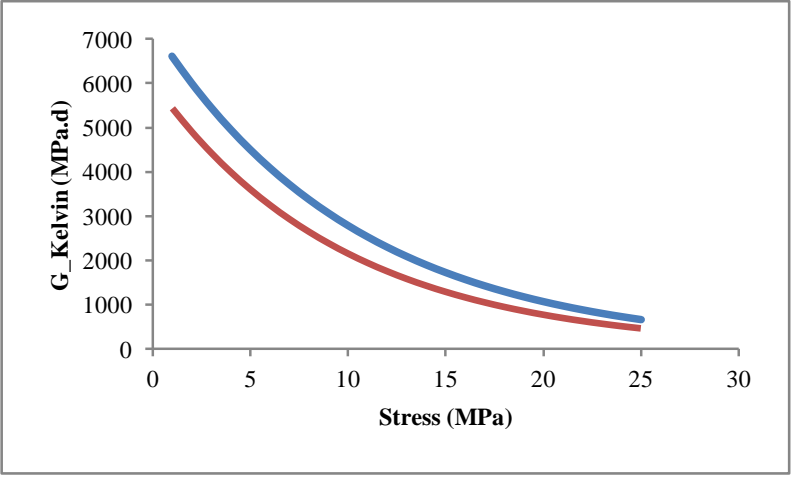

(b)

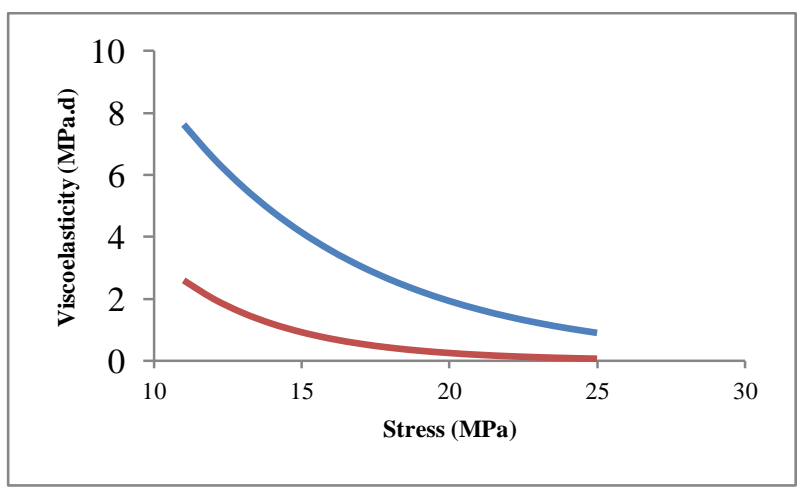

(c)

Figure9. A Viscoplastic, b-Kelvin module and c-Viscoelastic parameter of salt samples under quasi-static and cyclic test

\section{Conclusion}

This paper deals with the time-dependent behavior of salt caverns under cyclic application With regard to the assessment of long-term stability of the high frequency cyclic gas storage caverns. The transient and steady-state ratcheting behavior of the rock salt is analyzed in detail using uniaxial ratcheting experiments.

The time-dependent material behavior has an effect on the usability of the cavern because the creep of host rock results in cavern closure with long-term reduction in its volume. Also, high frequency cyclic pattern can intensify cavern volume loss. To take these effects into account, an efficient distinct nonlinear LUBBY2 constitutive model is used to simulate stress changes accurately.

Experimental investigations reveal that a higher injection/withdrawal frequency results in lower rock salt viscoelasticity and viscoplasticity. These time-dependent parameters decrease exponentially as frequency increases. But, viscoplasticity parameters are much more sensitive to the loading frequency than that of viscoelasticity components. The same results obtained for loading amplitude.

Thus, cavern depth accompanied by ratcheting strains show an effective influence on cavern closure and its volume loss. 


\section{ACKNOWLEDGEMENTS}

The authors would like to take this opportunity to thank the "Solution Mining Research Institute" for providing the related literature. Particular thanks go to Mr. Nader Ziyari for his great helps and suggestions in carrying out the experiments. Thanks are due to Mr. Fritz Crotogino, from KBB Underground, for his helps and supports.

\section{REFERENCES}

[1] Hunsche, U. and Hampel, A. Rock salt-the mechanical properties of the host material for radioactive waste repository. 1999, Engineering Geology, pp. 271-291.

[2] Zader-Schiebenhofer, D. High Frequency Cycling of Salt Storage Caverns (HFCSSC) Development of Appropriate Lab Tests \& Design Criteria-Step 1: Preliminary Study for a Detailed Definition of The Research Needs of the Industry in The Field of HFCSSC. Hannover : Solution Mining Research Institute, 2010.

[3] Carter, N.L. Rheology of salt rock1993, Journal of Structural Geology, pp. 1257-1272.

[4] Carter, N.L. and Hansen, F.D. Creep of rocksalt, a review. 1983, Tectonophysics, pp. 275-333.

[5] Cristescu, N. and Hunsche, U. A comprehensive constitutive equation for rock salt determination and application. Clausthal-Zellerfeld: Trans Tech Publications, 1996, In Proceedings of the Third Conference on the Mechanical Behavior of Salt, pp. 191-205.

[6] Fokker, Peter Anthonie. The Behavior of Salt And Salt Caverns. s.l. : PhD thesis, University of Delft, 1995.

[7] Jeremic, M. L. Rock mechanics in salt mining. Netherland : Balkema, 1994.

[8] Lomenick, T.F. and Bradshaw, R.L. Deformation of Rock Salt in Openings Mined for the Disposal of Radioactive Wastes. s.l. : Rock Mechanics, 1969, Vol. 1, pp. 5-30.

[9] Burdine, N.T. Rock failure under dynamic loading conditions. s.l. : Society of petroleum engineering journal, 1963, Vol. 3, pp. 1-8.

[10] Hardy, H.R. and Chung, Y.P. Failure of geologic materials under low cycle fatigue. Montreal : Proceedings of the sixth Canadian symposium on rock mechanics, 1970, pp. 33-47.

[11] Attewell, P.B. and Farmer, I.W. Fatigue behavior of rock. s.l. : International journal of rock mechanics and mining science, 1973, Vol. 10, pp. 1-9.

[12] Bagde, Manoj N. and Petros, Vladimir. Fatigue and dynamic energy behaviour of rock subjected to cyclical loading. 2009, International Journal of Rock Mechanics \& Mining Science, pp. 200209.

[13] Badge, M.N. and Petros, V. Fatigue properties of intact sandstone samples subjected to dynamic uniaxial cyclical loading. 2, s.l. : International journal of rock mechanics and mining science, 2005, Vol. 42, pp. 237-250.

[14] Thoms, R. L. and Gehle, R. Experimental study of rock salt for compressed air energy storage. 1982, SMRI symposium, pp. 991-1002.

[15] Passaris, E. K. Fatigue characteristics of rock salt with reference to underground storage caverns. S. 1982, Proceedings of SMRI symposium, pp. 983-989.

[16] Fuenkajorn, Kittitep and Phueakphum, Decho.Effects of cyclic loading on mechanical properties of Maha Sarakham salt. 2010, Engineering Geology, pp. 43-52.

[17] Heusermann, S., Rolfs, O. and Schmidt, U. Nonlinear finite-element analysis fo solution mined storage cavern in rock salt using the LUBBY2 constitutive model. 2003, Computer and Structures, pp. 629-638.

[18] Dresen, R. and Lux, Karl-Heinz. Method for Design of Salt Caverns with Respect to High Frequency Cycling of Storage Gas. Texas : SMRI, 2011.

[19] Gaudin, C. and Feaugas, X. Cyclic creep process in AISI 316L stainless steel in terms of dislocation patterns and internal stresses. 2004, Vol. 52.

[20] Lim, C.B., Kim, K.S. and Seong, J.B. Ratcheting and fatigue behaviour of a copper alloy under uniaxial cyclic loading with mean stress. s.l. : International Journal of Fatigue, 2009, Vol. 31.

[21] Cristescu, N. D. and Hunsche, U. Time Effects in Rock Mechanics. s.1. : WILEY \& SONS, 1998. 
[22] Jaeger, J.C., Cook, N.G.W. and Zimmerman, R.W. Fundamentals of rock mechanics. Singapore : Blackwell Publishing, 2007.

[23] Fuenkajorn, K. and Phueakphum, D. Effects of Cyclic Loading on the Mechanical Properties of Maha Sarakham Salt. 2, Thailand : Suranaree Journal of Science and Technology, 2009, Vol. 16, pp. 91-102.

[24] Allemandou, X. and Dusseault, M.B. Procedure for cyclic creep testing of salt rock, results and discussions. Clausthal-Zellerfeld : Proceedings of the 3rd conference on mechanical behavior of salt, Trans Tech Publications, 1996, pp. 207-218.

[25] Lux, K. H. and Heusermann, S. Creep test on rock salt with changing load as a basis for verification of theoritical material laws. Toronto : Wiley, 1983. 6th symposium on Salt. pp. 417430.

[26] Liang, W.G., et al. Effect of strain rate on the mechanical properties of salt rock. s.l. : International journal of rock mechanics and mining sciences, 2011, Vol. 48, pp. 161-167.

[27] Hosseini, S.M.A, Sereshki, F., Shariati, M., Jalali, SM.E., \& Crotogino, F. Development of a new creep testing equipment to obtain long-term deformation parameters of salt. Journal of Mining and Environment, 2012, Vol. 3.

[28] Xiao, J., Ding, D., Xu, G., \& Jiang, F. Waveform effect on quasi-dynamic loading condition and the mechanical properties of brittle materials. International Journal of Rock Mechanics and Mining Science, 2008, Vol. 45, pp. 621-626.

[29] ADINA R\&D, Inc. ADINA Theory and Modeling Guide. Watertown, US 